\title{
BIOATIVIDADE DO Bacillus thuringiensis var. kurstaki (Berliner, 1915) PARA ADULTOS DE Apis mellifera Linnaeus, 1758 (Hymenoptera: Apidae)
}

\author{
Bioactivity of Bacillus thuringiensis var. kurstaki (Berliner, 1915) to adults of \\ Apis mellifera Linnaeus, 1758 (Hymenoptera: Apidae)
}

\author{
Deodoro Magno Brighenti', César Freire Carvalho' ${ }^{2}$, Geraldo Andrade Carvalho², \\ Carla Regina G. Brighenti ${ }^{3}$, Stephan Malfitano Carvalho ${ }^{4}$
}

\begin{abstract}
RESUMO
Avaliou-se a influência do Bacillus thuringiensis var. kurstaki (Berliner) sobre adultos de Apis mellifera Linnaeus. Os experimentos foram realizados em laboratório a $28 \pm 2{ }^{\circ} \mathrm{C}$, UR $70 \pm 10 \%$ e fotofase de 12 horas. B. thuringiensis foi aplicado com pulverização sobre adultos, e fornecido através de solução aquosa de mel a $50 \%$ e em adição à pasta Cândi, utilizando o produto comercial Dipe $l^{\circledR}$ PM. Esse produto quando aplicado com pulverização ou incorporado à pasta Cândi ou à solução aquosa de mel provocou mortalidade de adultos de A. mellifera em todas as concentrações utilizadas, com exceção de $0,25 \mathrm{~g}$ de Dipel ${ }^{\circledR} / 100 \mathrm{~mL}$

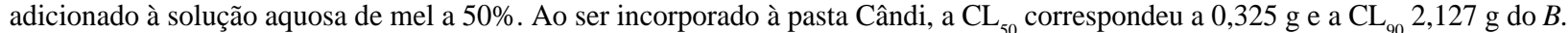
thuringiensis var. kurstaki/60 g de pasta. Adicionado à solução aquosa de mel a $50 \%, \mathrm{a} \mathrm{CL}_{50}$ foi de $1,403 \mathrm{~g}$ e a $\mathrm{CL}_{90}$ foi de $7,759 \mathrm{~g}$ do B. thuringiensis var. kurstaki/100 mL de solução. Sintomas de infecção pelo B. thuringiensis foram identificados nas abelhas adultas e através do isolamento obteve-se uma cultura dessa bactéria o que comprovou a patogenicidade para adultos de A. mellifera.
\end{abstract}

Termos para indexação: Abelha, toxicidade, inseticida biológico.

\begin{abstract}
The effects of Bacillus thuringiensis var. kurstaki (Berliner) on adults of Apis mellifera Linnaeus were evaluated. The bioassays were carried out under controlled conditions at $25 \pm 2^{\circ} \mathrm{C}, \mathrm{RH} 70 \pm 10 \%$ and 12 -h photophase. Adults of A. mellifera were exposed to the commercial product Dipel ${ }^{\circledR}$ PM. The following methods were used: direct spraying; supplying Bt with honey aqueous solution; and by a Candy paste added to Bt. B. thuringiensis caused mortality on A. mellifera adults, independent of the method used, except at $0.25 \mathrm{~g}$ of $\mathrm{Bt} / 100 \mathrm{~mL}$ added to the honey aqueous solution. B. thuringiensis added to the Candy paste showed $\mathrm{CL}_{50}$ and $\mathrm{CL}_{90}$ of $0.325 \mathrm{~g}$ and $2.127 \mathrm{~g}$ of the product to $60 \mathrm{~g}$ of Candy paste, respectively. Dipel ${ }^{\circledR} \mathrm{PM}$ added to the honey aqueous solution showed $\mathrm{CL}_{50}$ and $\mathrm{CL}_{90}$ of $1.403 \mathrm{~g}$ and $7.759 \mathrm{~g}$ of $B$. thuringiensis $/ 100 \mathrm{~mL}$, respectively. Infection symptoms by $B$. thuringiensis were identified on bees adult and by isolation of this bacterium, the toxicity of B. thuringiensis on A. mellifera was confirmed.
\end{abstract}

Index terms: Bee, toxicity, biological insecticide.

(Recebido em 24 de setembro de 2003 e aprovado em 22 de abril de 2005)

\section{INTRODUÇÃO}

As abelhas produzem cera para construção dos favos onde ocorre o armazenamento de pólen, mel e o desenvolvimento de ovos, larvas e pupas. Para o armazenamento dos favos de cera durante a entressafra é necessária a utilização de técnicas de conservação para evitar o aparecimento da traça Galleria mellonella (Linnaeus, 1758) (Lepidoptera: Pyralidae), encontrada no Brasil, em criações de abelhas, desde 1938 (SCHENK, 1938). As lagartas fazem galerias nos favos, alimentando-se de cera, pólen e mel, podendo destruí-los totalmente, impedindo sua reutilização (VANDENBERG \& SHIMANUKI, 1990b).
Em colônias com alta densidade populacional os favos não são prejudicados, porque as abelhas repelem as mariposas e, mesmo quando surgem algumas lagartas da traça, as operárias prontamente realizam a limpeza do favo, impedindo seu desenvolvimento (BURGES, 1978). No caso de baixa densidade populacional deve-se manejar corretamente a colméia, mantendo-se um número adequado de favos nas melgueiras (BURGES \& BAILEY, 1968). Além da destruição dos favos, lagartas e adultos da traça podem ser vetores de patógenos e, através das fezes, os adultos podem disseminar esporos das bactérias Paenibacillus larvae (White, 1906) causadora da "cria pútrida americana" e Melissococcus pluton (Bailey \&

\footnotetext{
'Zootecnista, Doutorando em Entomologia, M. Sc. Entomologia - Universidade Federal de Lavras/UFLA - Cx.P. 3037 - 37.200-000 - Lavras, MG - abelha @ ufla.br ${ }^{2}$ Professores do Departamento de Entomologia/DEN - Universidade Federal de Lavras/UFLA - Cx. P. 3037 - 37.200-000 - Lavras, MG ${ }^{3}$ Matemática, M. Sc., Doutoranda em Estatística e Experimentação Agropecuária - Universidade Federal de Lavras/UFLA - Cx. P. 3037 - 37.200-000 Lavras, MG.

${ }^{4}$ Agrônomo, Doutorando em Entomologia - Universidade Federal de Lavras/UFLA - Cx. P. 3037 - 37.200-000 - Lavras, MG.
} 
Collins, 1982) "cria pútrida européia" (ANDERSON, 1990).

Os prejuízos causados pela traça da cera têm incentivado pesquisadores a buscar métodos alternativos de controle, uma vez que a utilização de produtos químicos nas colméias e nos favos armazenados pode provocar a mortalidade de abelhas, contaminação do mel e demais produtos apícolas. Assim, dentre os métodos de controle empregados, tem-se sugerido o térmico, sendo normalmente de alto custo e de pouca eficiência (BOLLHALDER, 1999). Dessa forma, outras técnicas de controle desse inseto-praga, usando produtos de origem biológica, podem ser empregadas, como a utilização de entomopatógenos (VERMA, 1995). Dentre os produtos de origem microbiana comercializados no Brasil à base de Bacillus thuringiensis var. kurstaki (Berliner, 1915) destaca-se o Dipel ${ }^{\circledR} 32$ PM, que pode ser empregado no controle da traça da cera; contudo, ainda não foi registrado para proteção de favos (DIAS, 2001).

B. thuringiensis é uma bactéria "gram" positiva que, após a fase de crescimento, passa por um processo de esporulação devido à exaustão de nutrientes, produzindo um esporângio que contém um endosporo e inclusões cristalinas de proteínas que são responsáveis por sua ação entomopatogênica. Esse cristal protéico é composto por um polipeptídeo denominado endotoxina (NAVON, 1993). Quando formas larvais de um inseto alimentam-se dessas proteínas, inicia-se uma série de reações que culminam com a morte das mesmas, caracterizando, assim, o efeito do controle biológico (MENDONÇA, 2002). O emprego desse entomopatógeno é uma estratégia para o controle de lagartas não só por causa da sua especificidade, mas também por ser atóxico a seres humanos. Sua eficácia é maior quando ingerida pelas lagartas durante os primeiros ínstares, sendo considerado ineficaz para adultos (PEREIRA et al., 1998).

Segundo Burges \& Bailey (1968), formulações de B. thuringiensis incorporadas à cera alveolada durante o seu processamento não causaram efeitos prejudiciais às abelhas. Charrière \& Imdorf (1999) não encontraram resíduos na cera, mel, pólen e própolis, considerando a bactéria inócua para abelhas. Na Europa, alguns pesquisadores conseguiram resultados satisfatórios na conservação de favos, em que a incorporação de $B$. thuringiensis foi realizada durante o processo de fabricação da cera alveolada, permitindo o controle da traça da cera na entressafra (JYOTI \& BREWER, 1999; VANDENBERG \& SHIMANUKI, 1990a).
O método que melhor resultado tem proporcionado no controle da traça, apesar do aumento de mão-de-obra, é o emprego de $B$. thuringiensis por meio da pulverização dos favos (BAILEY, 1981; OIRSA, 1988; SINGH, 1962; SZABO \& HEIKEL, 1987). Dias (2001) mencionou que a conservação dos favos depois de vazios e limpos por meio de pulverização com Dipel $^{\circledR}$ e armazenamento em local fresco e arejado, pode evitar reinfestações de G. mellonella. Em Uttar Pradesh, na Índia, Verma (1995) utilizou uma formulação comercial de Dipel ${ }^{\circledR}$ testada em colônias de Apis cerana Fabricius, 1793 infestadas com esse piralídeo. A mortalidade média da traça foi de $98,7 \%$ aplicando-se 10 g de Dipel ${ }^{\circledR} / 1000 \mathrm{~mL}$ de água em pulverização, e a eficácia no controle desse inseto perdurou por 5,5 meses, sendo que as larvas das abelhas não foram afetadas.

Levando-se em consideração a importância que representa a traça da cera, tanto para colméias em condições de campo como também para favos que normalmente são armazenados na entressafra, o presente trabalho teve como objetivo avaliar o efeito de $B$. thuringiensis var. kurstaki em adultos de Apis mellifera Linnaeus, 1758.

\section{MATERIAL E MÉTODOS}

Abelhas do apiário experimental da UFLA foram coletadas dos favos de ninhos e transportadas em gaiolas teladas para laboratório. Para a avaliação da bioatividade de $B$. thuringiensis var. kurstaki sobre adultos de $A$. mellifera, foram utilizadas três formas de aplicação de Dipel $^{\circledR}$, encontrado na formulação pó molhável (PM), concentração de $32 \mathrm{~g} / \mathrm{kg}$ (16.000 unidades internacionais de potência por $\mathrm{mg}$, contendo um mínimo de 25 bilhões de esporos viáveis por grama, de acordo com seu fabricante). Pulverização de adultos - abelhas foram anestesiadas com $\mathrm{CO}_{2}$ por 120 segundos e pulverizadas com $10 \mathrm{~mL}$ da solução de Dipel ${ }^{\circledR}$ nas concentrações de 0,$25 ; 0,5 ; 1,0$; 2,5; 5,0;10,0 e 20,0 g em $100 \mathrm{~mL}$ de água destilada, utilizando um pulverizador manual com capacidade para $1000 \mathrm{~mL}$. Em seguida, os indivíduos tratados foram distribuídos em gaiolas de PVC de $15 \mathrm{~cm}$ de altura $\mathrm{x} 10 \mathrm{~cm}$ de diâmetro com a parte superior fechada com filó e a inferior com organza, sendo mantidas em sala climatizada a $28 \pm 2{ }^{\circ} \mathrm{C}$, UR de $70 \pm 10 \%$ e fotofase de 12 horas. Em cada gaiola foi colocado um chumaço de algodão embebido em água destilada e aproximadamente $6 \mathrm{~g}$ de pasta Cândi preparada com açúcar de confeiteiro e mel.

Adicionado à pasta Cândi - utilizaram-se as mesmas concentrações do Dipel ${ }^{\circledR}$ mencionadas anteriormente, sendo que cada uma foi incorporada à dieta artificial constituída por $60 \mathrm{~g}$ de pasta Cândi. Uma alíquota de $6 \mathrm{~g}$ 
da dieta contaminada foi colocada em um recipiente plástico de $25 \mathrm{~mm}$ de diâmetro x $5 \mathrm{~mm}$ de altura, o qual foi mantido sobre cada gaiola de PVC de $15 \mathrm{~cm}$ de altura x $10 \mathrm{~cm}$ de diâmetro para alimentação dos adultos. Colocou-se também chumaço de algodão embebido em água destilada, a qual foi reposta sempre que necessário.

Adicionado à solução aquosa de mel a $\mathbf{5 0 \%}$ - empregaramse as mesmas concentrações do Dipel ${ }^{\circledR}$ em $100 \mathrm{~mL}$ de solução aquosa de mel a 50\%, fornecendo em cada gaiola, um recipiente de vidro com capacidade para $20 \mathrm{~mL}$, contendo a tampa perfurada, por onde foi inserido um rolo dentário de algodão umedecido na solução aquosa de mel com a respectiva concentração de Dipel ${ }^{\circledR}$, para alimentação das abelhas.

Nas três formas de aplicação foi utilizado o delineamento inteiramente ao acaso, com oito tratamentos e dez repetições, sendo cada uma formada por 10 indivíduos. Avaliou-se a mortalidade das abelhas às 1, 3 e 6h após a aplicação do Dipel ${ }^{\circledR}$ e posteriormente a cada $6 \mathrm{~h}$ até completar $96 \mathrm{~h}$ da liberação dos insetos nas gaiolas, a fim de estimar o período de sobrevivência de A. mellifera. A mortalidade total em cada tratamento foi corrigida através da fórmula de Abbott (1925).

Aplicou-se teste de médias de agrupamento de Scott \& Knott (1974) $(\mathrm{P}<0,05)$. Os dados de mortalidade foram submetidos à análise de Probit, determinando-se curvas de concentração-mortalidade para os três bioensaios, e por meio destas, foram estimados os valores de $\mathrm{CL}_{50}$ e $\mathrm{CL}_{90}$ (FINNEY, 1971). O teste $\chi^{2}$ foi usado para medir o ajuste dos pontos da reta probítica. Posteriormente, avaliou-se a sobreposição ou não do intervalo de confiança (IC) das $\mathrm{CL}_{50}$ e $\mathrm{CL}_{90}$ estimadas. A sobreposição do IC foi interpretada como igualdade de tratamentos. O nível de significância dos testes foi de $\alpha=0,05$.

Os dados de mortalidade ao longo do tempo para cada repetição foram ajustados utilizando o modelo Probit (PREISLER \& ROBERTSON, 1989). Calculou-se o tempo letal médio $\left(\mathrm{TL}_{50}\right.$ - tempo estimado para $50 \%$ de mortalidade dos indivíduos) e a longevidade média (quociente da soma das longevidades individuais, pelo número de indivíduos). Para cada concentração aplicada, um $\mathrm{TL}_{50}$ e seu erro padrão foi calculado, e estabelecido um intervalo de confiança (IC $95 \%$ ). A sobreposição do IC foi interpretada como igualdade de tratamentos. O nível de significância dos testes foi de $\alpha=0,05$.

As abelhas mortas foram colocadas em placas de Petri e conservadas em freezer a uma temperatura de $-18^{\circ} \mathrm{C}$ para posterior isolamento do Bacillus e confirmação da presença da bactéria como a responsável pela mortalidade dos adultos.
O isolamento de $B$. thuringiensis nas abelhas foi realizado no Laboratório de Bacteriologia do Departamento de Fitopatologia da UFLA, conforme metodologia proposta por Chaves et al. (1973) $)^{5}$ citados por Zanuncio (1976). Em câmara de fluxo laminar colocou-se em uma placa de Petri uma alíquota de cinco abelhas de cada tratamento para cada bioensaio. Acrescentou-se álcool a 70\% até a completa imersão das abelhas por 30 segundos, em seguida foram transferidas para outra placa com solução de hipoclorito de sódio a $2 \%$ por cinco minutos. Posteriormente, foram colocadas em uma nova placa com água destilada, para retirar o excesso de hipoclorito de sódio, sendo, em seguida, maceradas e colocadas em tubos de vidro de $2,5 \mathrm{~cm}$ de diâmetro $\mathrm{x} 8 \mathrm{~cm}$ de altura.

Para eliminação de organismos saprófitos, os tubos de vidro foram colocados em banho-maria a $80^{\circ} \mathrm{C}$ por 20 minutos, uma vez que as bactérias do gênero Bacillus são resistentes a temperaturas mais altas. Em seguida, foram feitas duas placas por tratamento (repicagens) para meio de cultura (Meio Básico I - MBI) composto de $10 \mathrm{~g}$ de sacarose, $4 \mathrm{~g}$ de extrato de lêvedo, $8 \mathrm{~g}$ de caseína ácida hidrolisada, $2 \mathrm{~g}$ de $\mathrm{K}_{2} \mathrm{HPO}_{4}$ (anidro), 0,3 g de $\mathrm{MgSO}_{4}, 20 \mathrm{~g}$ de ágar e $1000 \mathrm{~mL}$ de água destilada (KADO \& HESKETT, 1970). Ao término, as placas foram levadas para câmara climatizada em ausência de luz, regulada a $30 \pm 2^{\circ} \mathrm{C}$ por $24 \mathrm{~h}$, período suficiente para o crescimento da cultura de $B$. thuringiensis var. kurstaki. O produto comercial Dipel ${ }^{\circledR}$ também foi diluído em água esterilizada e transferido para tubo de vidro. Em seguida, foram feitas as repicagens para o meio de cultura MBI para caracterização e comparação das culturas nas placas.

\section{RESULTADOS E DISCUSSÃO}

Pulverização de adultos - o composto Dipel ${ }^{\circledR}$ quando aplicado em pulverização provocou mortalidade significativa das abelhas. Os maiores índices ocorreram nas concentrações de 0,$25 ; 0,5 ; 1,0$ e 10,0 g/100 mL, com mortalidade média de 62,$2 ; 52,4 ; 54,1$ e $45,9 \%$, respectivamente (Tabela 1 ).

A variação de mortalidade provavelmente ocorreu devido a diferenças de idades dos indivíduos, visto que em abelhas mais jovens, os comportamentos de higiene e lambedura são mais acentuados, o que pode ter propiciado maior ingestão de esporos da bactéria e conseqüentemente maior mortalidade.

${ }^{5}$ CHAVES, G.; CARVALHO, M. G.; CRUZ-FILHO, J.; ROMEIRO, R. S. Roteiro de aulas de fitopatologia. Viçosa: UFV, 1973. $58 \mathrm{p}$. 
TABELA 1 - Mortalidade $(\%)( \pm \mathrm{EP})^{1}$ de adultos de Apis mellifera após 96 horas da pulverização com Dipel ${ }^{\circledR} 32$ PM. Temperatura de $28 \pm 2^{\circ} \mathrm{C}$, UR de $70 \pm 10 \%$ e fotofase de 12 horas.

\begin{tabular}{ccc}
\hline Dipel $^{\circledR}(\mathbf{g} / \mathbf{1 0 0} \mathbf{~ m L}$ de água $)$ & Mortalidade & Mortalidade corrigida $^{\mathbf{2}}$ \\
\hline 0,00 & $39,0 \pm 0,4 \mathrm{a}$ & 0,0 \\
0,25 & $77,0 \pm 1,1 \mathrm{c}$ & 62,2 \\
0,50 & $71,0 \pm 1,4 \mathrm{c}$ & 52,4 \\
1,00 & $72,0 \pm 0,7 \mathrm{c}$ & 54,1 \\
2,50 & $57,0 \pm 0,5 \mathrm{~b}$ & 29,5 \\
5,00 & $53,0 \pm 0,6 \mathrm{~b}$ & 22,9 \\
10,0 & $67,0 \pm 0,4 \mathrm{c}$ & 45,9 \\
20,0 & $56,0 \pm 0,3 \mathrm{~b}$ & 27,9 \\
\hline C.V. & 17,7 & - \\
\hline
\end{tabular}

Médias seguidas pela mesma letra minúscula nas colunas não diferem significativamente entre si, pelo teste de ScottKnott a 5\% de probabilidade.

${ }^{1}$ Erro Padrão.

${ }^{2}$ Mortalidade corrigida pela fórmula de Abbott (1925).

${ }^{3}$ Coeficiente de Variação.

Não foi possível estimar a $\mathrm{CL}_{50}$, pois os dados não se ajustaram ao modelo de Probit.

As abelhas que receberam o tratamento com $B$. thuringiensis sobreviveram, em média, de 1,6 a 3,1 dias (Tabela 2).

Pela sobreposição dos intervalos de confiança, pode-se verificar que o $\mathrm{TL}_{50}$ não diferiu para as dosagens testadas, quando da aplicação do Dipe ${ }^{\circledR}$ em pulverização.

A mortalidade pela aplicação do Dipel $^{\circledR} \mathrm{em}$ pulverização pode ter ocorrido por duas causas. Uma delas seria o comportamento higiênico no qual a limpeza do tegumento de uma abelha pela outra, pode ter provocado maior ingestão do produto. A outra poderia ser o comprometimento da respiração desses insetos, tendo ocorrido mortalidade mesmo antes da ação da bactéria nos seus intestinos, principalmente nas concentrações mais altas. Estes fatos, possivelmente, explicam a variação na longevidade, pois foi verificado maior porcentagem de mortalidade logo após a pulverização. Observou-se que o $\mathrm{TL}_{50}$ foi elevado, provavelmente, depois de realizada a limpeza, não houve mais contato das abelhas restantes com a bactéria.

Adicionado à pasta Cândi - observaram-se dois grupos distintos de porcentagem de mortalidade pelo Dipel ${ }^{\circledR}$. No primeiro, concentrações entre 0,25 e $1 \mathrm{~g}$ do produto/60 $\mathrm{g}$ da pasta Cândi causaram mortalidade entre 54 e $68 \%$ (Tabela 3). No segundo, a mortalidade foi superior a $94 \%$, chegando a $100 \%$, em apenas $72 \mathrm{~h}$, nas concentrações de 10 e $20 \mathrm{~g}$, evidenciando o elevado efeito do produto na mortalidade.
Verificou-se que os dados se ajustaram ao modelo probit (FINNEY, 1971) $\left(\chi^{2}=6,87 ; \mathrm{gl}=5 ; \mathrm{p}>0,05\right)$ determinado pela equação:

Probabilidade de mortalidade $=\frac{1}{\sqrt{2 \pi}} \int_{-\infty}^{\hat{y}} \exp \left[-\frac{x^{2}}{2}\right] d x$

em que : $\quad \hat{y}=[-0,7667+1,5711 * \log ($ concentração $)]$

Foi constatado que nas concentrações de $0,325 \mathrm{~g}$ $\left(\mathrm{IC}_{95 \%}[0,2 ; 0,453]\right)$ e 2,127 g/60 g de pasta Cândi $\left(\mathrm{IC}_{95 \%}\right.$ $[1,571 ; 3,239])$ de $B$. thuringiensis var. kurstaki/60 $\mathrm{g}$ de pasta Cândi ocorreram 50 e $90 \%$ de mortalidade de adultos de A. mellifera, respectivamente (Figura 1).

O coeficiente angular da curva concentraçãomortalidade $(b=1,5711)$ é inverso ao desvio padrão da distribuição da tolerância ao inseticida biológico. Dessa forma, maiores coeficientes angulares indicam menor variação na resposta da população ao inseticida.

A longevidade média de abelhas adultas variou entre 2,6 a 3,1 dias (Tabela 4). Na aplicação do Dipel ${ }^{\circledR}$ por adição à pasta Cândi o $\mathrm{TL}_{50}$ não diferiu para as dosagens de 0,$25 ; 0,5$ e $1,0 \mathrm{~g}$ pela sobreposição dos intervalos de confiança. Observou-se que em função do aumento das concentrações o tempo letal médio foi diminuindo, evidenciando uma ação relativamente rápida do produto.

Ciênc. agrotec., Lavras, v. 31, n. 2, p. 279-289, mar./abr., 2007 
TABELA 2 - Longevidade média (horas) $( \pm \mathrm{EP})^{1}$ e tempo letal de $50 \%\left(\mathrm{TL}_{50}\right)$ de mortalidade de adultos de Apis mellifera pulverizados com Dipel ${ }^{\circledR} 32$ PM. Temperatura de $28 \pm 2^{\circ} \mathrm{C}$, UR de $70 \pm 10 \%$ e fotofase de 12 horas.

\begin{tabular}{ccc}
\hline Dipel $^{\circledR}(\mathbf{g} / \mathbf{1 0 0} \mathbf{~ m L}$ de água $)$ & Longevidade & TL $_{\mathbf{5 0}}(\mathbf{I C ~ 9 5 , 0 \%})$ \\
\hline 0,25 & $74,64 \pm 21,79 \mathrm{a}$ & $73,31(66,32 ; 81,03)$ \\
0,50 & $74,19 \pm 21,09 \mathrm{a}$ & $76,57(69,65 ; 84,18)$ \\
1,00 & $75,42 \pm 21,17 \mathrm{a}$ & $75,67(68,27 ; 83,88)$ \\
2,50 & $60,00 \pm 17,68 \mathrm{~b}$ & $86,31(75,61 ; 98,53)$ \\
5,00 & $47,07 \pm 16,29 \mathrm{c}$ & $90,12(76,70 ; 105,90)$ \\
10,0 & $43,17 \pm 13,19 \mathrm{c}$ & $67,56(55,58 ; 82,12)$ \\
20,0 & $38,52 \pm 9,77 \mathrm{c}$ & $85,28(67,65 ; 107,50)$ \\
\hline C.V.
\end{tabular}

Médias seguidas de mesma letra não diferem significativamente entre si, pelo teste de Scott- Knott a 5\% de probabilidade. ${ }^{1}$ Erro Padrão. , ${ }^{2}$ Coeficiente de Variação.

TABELA 3 - Mortalidade (\%) ( \pm EP $)^{1}$ de adultos de Apis mellifera após 96 horas da alimentação com pasta Cândi contendo Dipel ${ }^{\circledR} 32$ PM. Temperatura de $28 \pm 2^{\circ} \mathrm{C}$, UR de $70 \pm 10 \%$ e fotofase de 12 horas.

\begin{tabular}{ccc}
\hline Dipel $^{\circledR}(\mathbf{g} / \mathbf{6 0}$ g de pasta Cândi) & Mortalidade & Mortalidade corrigida $^{2}$ \\
\hline 0,00 & $41,0 \pm 0,9 \mathrm{a}$ & 0,0 \\
0,25 & $73,0 \pm 0,4 \mathrm{~b}$ & 54,2 \\
0,50 & $75,0 \pm 0,5 \mathrm{~b}$ & 57,6 \\
1,00 & $81,0 \pm 0,3 \mathrm{~b}$ & 67,8 \\
2,50 & $97,0 \pm 0,2 \mathrm{c}$ & 94,9 \\
5,00 & $98,0 \pm 0,1 \mathrm{c}$ & 96,6 \\
10,0 & $100,0 \pm 0,0 \mathrm{c}$ & 100,0 \\
20,0 & $100,0 \pm 0,0 \mathrm{c}$ & 100,0 \\
\hline C.V. ${ }^{3}(\%)$ & 9,4 &
\end{tabular}

Médias seguidas pela mesma letra minúscula nas colunas não diferem significativamente entre si, pelo teste de ScottKnott a $5 \%$ de probabilidade.

${ }^{1}$ Erro Padrão.,${ }^{2}$ Mortalidade corrigida pela fórmula de Abbott (1925).,${ }^{3}$ Coeficiente de Variação.

TABELA 4 - Longevidade média (horas) $( \pm \mathrm{EP})^{1}$ e tempo letal de $50 \%\left(\mathrm{TL}_{50}\right)$ de mortalidade de adultos de Apis mellifera em função de diferentes concentrações de Dipel ${ }^{\boxplus} 32 \mathrm{PM}$ adicionadas à pasta Cândi. Temperatura de $28 \pm 2^{\circ} \mathrm{C}$, UR de $70 \pm 10 \%$ e fotofase de 12 horas.

\begin{tabular}{ccc}
\hline Dipel $^{\circledR}(\mathbf{g} / \mathbf{6 0}$ g de pasta Cândi) & Longevidade Média & TL $_{\mathbf{5 0}}(\mathbf{I C} \mathbf{9 5 , 0 \%})$ \\
\hline 0,25 & $70,71 \pm 26,49 \mathrm{a}$ & $78,23(72,10 ; 84,89)$ \\
0,50 & $72,09 \pm 23,66 \mathrm{a}$ & $77,49(71,90 ; 83,52)$ \\
1,00 & $71,52 \pm 25,66 \mathrm{a}$ & $77,99(73,23 ; 83,06)$ \\
2,50 & $73,98 \pm 25,63 \mathrm{a}$ & $60,31(56,70 ; 64,16)$ \\
5,00 & $73,20 \pm 27,61 \mathrm{a}$ & $46,43(43,05 ; 50,07)$ \\
10,0 & $63,30 \pm 33,41 \mathrm{a}$ & $43,14(40,50 ; 45,96)$ \\
20,0 & $69,39 \pm 32,25 \mathrm{a}$ & $38,86(36,90 ; 40,93)$ \\
\hline
\end{tabular}

Médias seguidas de mesma letra não diferem significativamente entre si, pelo teste de Scott- Knott a 5\% de probabilidade. ${ }^{1}$ Erro Padrão. , ${ }^{2}$ Coeficiente de Variação. 


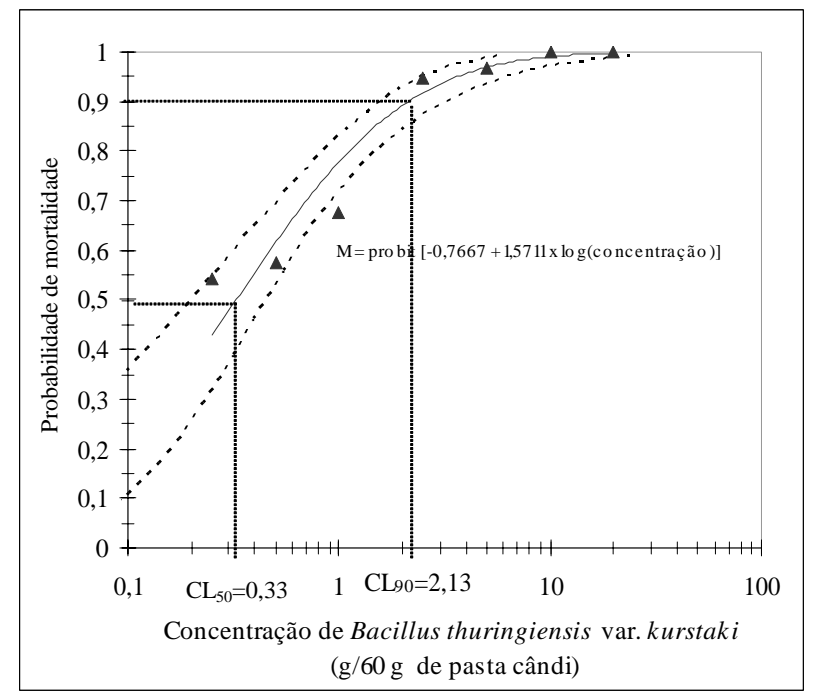

FIGURA 1 - Curva de concentração-mortalidade de adultos de Apis mellifera em função de diferentes concentrações de Dipel ${ }^{\circledR} 32$ PM adicionadas à pasta Cândi.

Adicionado à solução aquosa de mel a $\mathbf{5 0 \%}$ - à exceção de $0,25 \mathrm{~g}$ de $\operatorname{Dipel}^{\circledR} / 100 \mathrm{~mL}$, as demais concentrações causaram mortalidade significativa das abelhas. As concentrações de 10 e $20 \mathrm{~g} / 100 \mathrm{~mL}$, apresentaram as maiores médias de mortalidade, sendo de 94,7 e $98,2 \%$, respectivamente, e a 2,5 e 5 g de Dipel ${ }^{\circledR} / 100 \mathrm{~mL}$ apresentaram médias de 73,7 e $75,4 \%$, respectivamente. Observou-se mortalidade de $33,3 \%$ para as concentrações de 0,5 e $1 \mathrm{~g}$ do produto/100 $\mathrm{mL}$ (Tabela 5).

Os dados do efeito da concentração do $B$. thuringiensis var. kurstaki adicionado à solução aquosa de mel a 50\% sobre a mortalidade das abelhas se ajustaram ao modelo Probit (FINNEY, 1971) $\left(\chi^{2}=6,64 ; \mathrm{gl}=5 ; \mathrm{p}>\right.$ $0,05)$, sendo determinado pela equação:

Probabilidade de mortalidade $=\frac{1}{\sqrt{2 \pi}} \int_{-\infty}^{\hat{y}} \exp \left[-\frac{x^{2}}{2}\right] d x$ em que: $\quad \hat{y}=\left[-0,2538+1,7255^{*} \log (\right.$ concentração $\left.)\right]$

Verificou-se que nas concentrações de $1,403 \mathrm{~g}\left(\mathrm{IC}_{95 \%}\right.$ $[1,017 ; 1,820])$ e $7,759 \mathrm{~g} / 100 \mathrm{~mL}$ de solução aquosa de mel ( $\left.\mathrm{IC}_{95 \%}[5,744 ; 11,672]\right)$ do B. thuringiensis. var. kurstaki / 100 mL de solução aquosa de mel ocorreram 50 e $90 \%$ de mortalidade de abelhas, respectivamente (Figura 2).

A diferença nas metodologias de aplicação foi evidenciada pela não sobreposição dos intervalos de confiança da $\mathrm{CL}_{50}$ do B. thuringiensis var. kurstaki adicionado à pasta Cândi com o IC obtido no bioensaio via solução aquosa de mel. As estimativas da $\mathrm{CL}_{50}$ e da $\mathrm{CL}_{90}$ foram, respectivamente, 4,3 e 3,6 vezes menores, na metodologia por adição à pasta Cândi do que na adição em solução aquosa de mel.

O coeficiente angular, da curva concentraçãomortalidade, obtido a partir da análise de Probit na metodologia por adição de $B$. thuringiensis var. kurstaki via solução aquosa de mel a $50 \%$, foi de $b=1,7255$ e próximo ao coeficiente obtido no bioensaio de pasta Cândi, indicando semelhança na variabilidade de resposta entre as abelhas utilizadas nos dois bioensaios, ou ainda, homogeneidade das populações testadas.

$\mathrm{Na}$ aplicação do Dipel ${ }^{\circledR}$ em solução aquosa de mel, o $\mathrm{TL}_{50}$ não diferiu para as concentrações de 10 e $20 \mathrm{~g}$ pela sobreposição dos intervalos de confiança. A longevidade média dos adultos de abelhas variou entre 2,3 a 3,2 dias (Tabela 6).

A concentração de $0,25 \mathrm{~g} \mathrm{Dipel}^{\circledR} / 100 \mathrm{~mL}$ de solução aquosa de mel não causou mortalidade superior a $50 \%$ durante o período de 96 horas (Tabela 6). O maior $\mathrm{TL}_{50}$ obtido foi o de 84,2 horas correspondente à concentração de $1 \mathrm{~g} / 100 \mathrm{~mL}$, o que indica uma possibilidade de utilização do produto em concentrações inferiores a este valor uma vez que a $\mathrm{CL}_{50}$ obtida quando se utilizou essa metodologia foi de $1,403 \mathrm{~g} / 100 \mathrm{~mL}$. 
TABELA 5 - Mortalidade $(\%)( \pm \mathrm{EP})^{1}$ de adultos de Apis mellifera após 96 horas da alimentação com solução aquosa de mel a $50 \%$ contendo Dipel ${ }^{\circledR} 32$ PM. Temperatura de $28 \pm 2{ }^{\circ} \mathrm{C}$, UR de $70 \pm 10 \%$ e fotofase de 12 horas.

\begin{tabular}{|c|c|c|}
\hline $\begin{array}{c}\text { Dipel }^{\circledR}(\mathrm{g} / 100 \mathrm{~mL} \text { de solução } \\
\text { aquosa de mel a } 50 \%)\end{array}$ & Mortalidade & $\begin{array}{c}\text { Mortalidade } \\
\text { corrigida }\end{array}$ \\
\hline 0,00 & $43,0 \pm 0,4 \mathrm{a}$ & 0,0 \\
\hline 0,25 & $44,0 \pm 0,5 \mathrm{a}$ & 1,8 \\
\hline 0,50 & $62,0 \pm 0,5 b$ & 33,3 \\
\hline 1,00 & $62,0 \pm 0,5 \mathrm{~b}$ & 33,3 \\
\hline 2,50 & $85,0 \pm 0,2 \mathrm{c}$ & 73,7 \\
\hline 5,00 & $86,0 \pm 0,3 \mathrm{c}$ & 75,4 \\
\hline 10,0 & $97,0 \pm 0,2 \mathrm{~d}$ & 94,7 \\
\hline 20,0 & $99,0 \pm 0,1 \mathrm{~d}$ & 98,2 \\
\hline C.V..$^{3}(\%)$ & 11,2 & \\
\hline
\end{tabular}

Médias seguidas pela mesma letra minúscula nas colunas não diferem significativamente entre si, pelo teste de Scott-Knott a 5\% de probabilidade. , ${ }^{1}$ Erro Padrão. , ${ }^{2}$ Mortalidade corrigida pela fórmula de Abbott (1925)., ${ }^{3}$ Coeficiente de Variação.

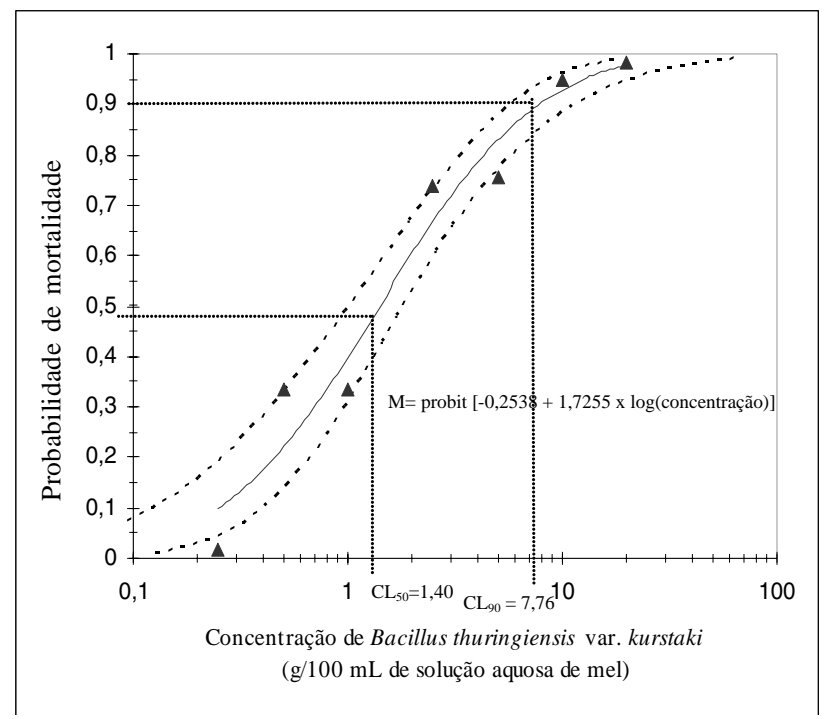

FIGURA 2 - Curva de concentração-mortalidade de adultos de Apis mellifera em função de diferentes concentrações de Dipel ${ }^{\circledR} 32$ PM adicionadas à solução aquosa de mel a $50 \%$.

TABELA 6 - Longevidade média (horas) $( \pm \mathrm{EP})^{1}$ e tempo letal de $50 \%\left(\mathrm{TL}_{50}\right)$ de mortalidade de adultos de Apis mellifera alimentados com Dipel ${ }^{\circledR}$ em solução aquosa de mel a $50 \%$. Temperatura de $28 \pm 2{ }^{\circ} \mathrm{C}$, UR $70 \pm 10 \%$ e fotofase de 12 horas.

\begin{tabular}{ccc}
\hline $\begin{array}{c}\text { Dipel }^{\circledR}(\mathbf{g} / \mathbf{1 0 0} \mathbf{~ m L ~ d e ~ s o l u c ̧ a ̃ o ~} \\
\text { aquosa de mel) }\end{array}$ & Longevidade Média & TL $_{\mathbf{5 0}}(\mathbf{I C} \mathbf{9 5 , 0} \%)$ \\
\hline 0,25 & $76,86 \pm 28,40 \mathrm{a}$ & --- \\
0,50 & $70,68 \pm 29,56 \mathrm{a}$ & $80,19(69,35 ; 92,72)$ \\
1,00 & $74,82 \pm 26,59 \mathrm{a}$ & $84,20(75,05 ; 94,46)$ \\
2,50 & $63,42 \pm 27,29 \mathrm{a}$ & $63,76(57,38 ; 70,85)$ \\
5,00 & $70,02 \pm 24,47 \mathrm{a}$ & $71,50(66,06 ; 77,39)$ \\
10,0 & $54,12 \pm 21,64 \mathrm{~b}$ & $53,22(48,77 ; 58,07)$ \\
20,0 & $54,39 \pm 19,49 \mathrm{~b}$ & $53,84(49,92 ; 58,17)$ \\
\hline C.V.
\end{tabular}

Médias seguidas de mesma letra não diferem significativamente entre si, pelo teste de Scott- Knott a 5\% de probabilidade. ${ }^{1}$ Erro Padrão. , ${ }^{2}$ Coeficiente de Variação. 
Comparando-se as três formas de aplicação, constatou-se menor mortalidade através da aplicação em solução aquosa de mel a $50 \%$ até a concentração de $1 \mathrm{~g}$; acima dessa, o método em que se constatou menor mortalidade foi a de pulverização. A mortalidade causada pela aplicação de $0,5 \mathrm{~g}$ de $\operatorname{Dipel}^{\circledR}$ não diferiu significativamente entre as formas de aplicação. A partir de 2,5 g não houve diferença entre os resultados, quando da adição em pasta Cândi e solução aquosa de mel a 50\%. Com relação à testemunha, a mortalidade foi significativamente mais baixa e não diferiu entre as metodologias empregadas (Figura 3).

Quanto à longevidade média, observou-se que nas três metodologias os menores valores foram obtidos nas concentrações de 10 e $20 \mathrm{~g}$ de Dipel $^{\circledR}$. A maior variabilidade da longevidade ocorreu na metodologia de aplicação por pulverização (entre 75,42 e 38,52 horas) (Tabela 2), e a menor na pasta Cândi, onde a longevidade média variou entre 73,98 e 63,30 horas (Tabela 4). É importante notar que a longevidade média no caso da aplicação por pulverização, praticamente não diferiu para as dosagens de 0,25; 0,5 e 1 $\mathrm{g}$ de Dipel ${ }^{\circledR}$, e foi decrescente com o aumento das demais dosagens, fato não constatado nas outras metodologias.

A vantagem do método de aplicação por pulverização em laboratório é que as abelhas são expostas principalmente pelo contato direto, como ocorre durante $\mathrm{o}$ forrageamento em culturas onde é utilizado o Dipel ${ }^{\circledR}$ para controle de insetos-praga. Dias (2001) sugeriu a conservação dos favos, pulverizando-os com Dipel ${ }^{\circledR}$; entretanto, não eram conhecidos os efeitos deletérios desse produto para larvas e/ou adultos de A. mellifera.

$\mathrm{O}$ isolamento de $B$. thuringiensis em abelhas retiradas dos tratamentos, nas três formas de aplicação do inseticida biológico, foi realizado pelo método MBI, totalizando 24 placas de cultura. Após 24 horas do isolamento, fez-se a comparação dos isolados dos tratamentos com a cultura obtida diretamente do produto comercial Dipel $^{\circledR}$. Os isolados de todos os tratamentos, à exceção da testemunha, foram considerados idênticos, comprovando-se ser o mesmo microrganismo patogênico para todos os grupos de abelhas utilizados.

Os sintomas externos provocados pelo $B$. thuringiensis em adultos de A. mellifera não eram conhecidos, uma vez que esse produto é indicado para controle de lagartas de lepidópteros, larvas de coleópteros e dípteros. Foi observado que o comportamento de limpeza do corpo e de agregação noturna das abelhas adultas foi alterado. Nas primeiras horas após o fornecimento do produto na pasta Cândi e solução aquosa de mel, houve rejeição do alimento, principalmente quando utilizadas concentrações mais altas, fato não ocorrido na aplicação por pulverização. Possivelmente, distúrbios intestinais

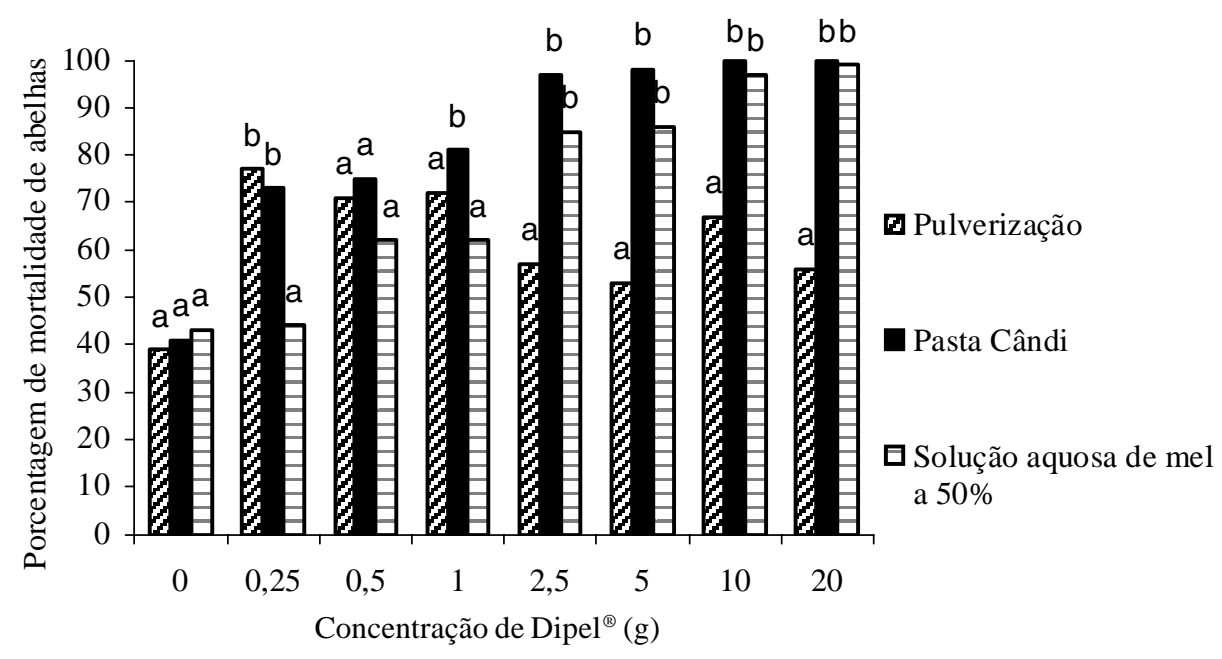

FIGURA 3 - Porcentagens de mortalidade de adultos de Apis mellifera submetidos a diferentes metodologias de aplicação do Dipel ${ }^{\circledR} 32 \mathrm{PM}$. Temperatura de $28 \pm 2{ }^{\circ} \mathrm{C}$, UR de $70 \pm 10 \%$ e fotofase de 12 horas.

Ciênc. agrotec., Lavras, v. 31, n. 2, p. 279-289, mar./abr., 2007 
passaram a ocorrer, pois grande fluxo de fezes liqüefeitas foi encontrado nas paredes da gaiola, aspecto não presente no tratamento testemunha. Quando os adultos foram pulverizados, notou-se a presença de fezes das abelhas na dieta posicionada na parte superior da gaiola.

Também foi realizado o isolamento do $B$. thuringiensis pelo método MBI, na pasta Cândi com resíduos de fezes obtidos do experimento por pulverização. A cultura obtida foi idêntica ao isolamento realizado com o produto comercial Dipel ${ }^{\circledR}$, confirmando a passagem desta bactéria pelo trato intestinal destes insetos.

Constatou-se também um aumento de 20 a $30 \%$ do volume do abdome de abelhas que foram submetidas aos tratamentos com maiores concentrações do Dipel ${ }^{\circledR}$, independente do método de aplicação utilizado (Figura 4). Houve perda de agilidade, observando-se a presença de abelhas caminhando lentamente, com posterior paralisia geral antes de morrer. Indivíduos vivos tentavam retirar, do fundo do recipiente, as abelhas mortas nas primeiras $60 \mathrm{~h}$ da aplicação do produto, caminhando com o adulto morto para a lateral da gaiola, preso em suas mandíbulas, comportamento característico das abelhas, como descrito por Gramacho (2002). Após esse período não foi observado o hábito de limpeza, aumentando o número de indivíduos que se mantinham isolados durante a noite, o que não ocorreu no tratamento testemunha, quando se mantiveram sempre agregados.

Foram observadas modificações evidentes no comportamento, sobrevivência e longevidade em todos as metodologias empregadas. Verma (1995), na Índia, relatou que não houve mortalidade de larvas e adultos de A. cerana pulverizados com Dipel ${ }^{\circledR}$, provavelmente por se tratar de uma outra espécie de abelha. Brighenti et al. (2002) e Carvalho et al. (2002) mencionaram que Dipel ${ }^{\circledR}$ foi inócuo para as abelhas com concentrações inferiores às utilizadas neste trabalho. Os resultados obtidos confirmaram o efeito deletério de $B$. thuringiensis para adultos de abelhas nestas concentrações e de acordo com Sebesta \& Horska (1970) ${ }^{6}$, citados por Arantes (1989), a b-exotoxina pode causar envenenamento nos adultos. Heimpel \& Angus (1960) relataram que lepidópteros adultos da família Geometridae e abelhas são susceptíveis aos esporos de B. thuringiensis.

Levando-se em consideração a necessidade de controle da traça, torna-se necessário o desenvolvimento de outras pesquisas, como, por exemplo, o efeito dessa bactéria sobre adultos e larvas de A. mellifera após o período de armazenamento dos favos tratados na entressafra, ou mesmo no mel e em outros derivados, em concentrações menores. Burges \& Bailey (1968) e Charrière \& Imdorf (1999), em suas pesquisas, não encontraram resíduos de $B$. thuringiensis aizawai na cera, pólen e própolis e consideraram o produto inócuo às abelhas.

${ }^{6}$ SEBESTA, K.; HORSKÁ, K. Mechanism of inhibition od DNA dependent RNA polymerase by exotoxin of Bacillus thuringiensis. Biochimica Biophysica Acta, Amsterdam, v. 209, p. 357-367, 1970.

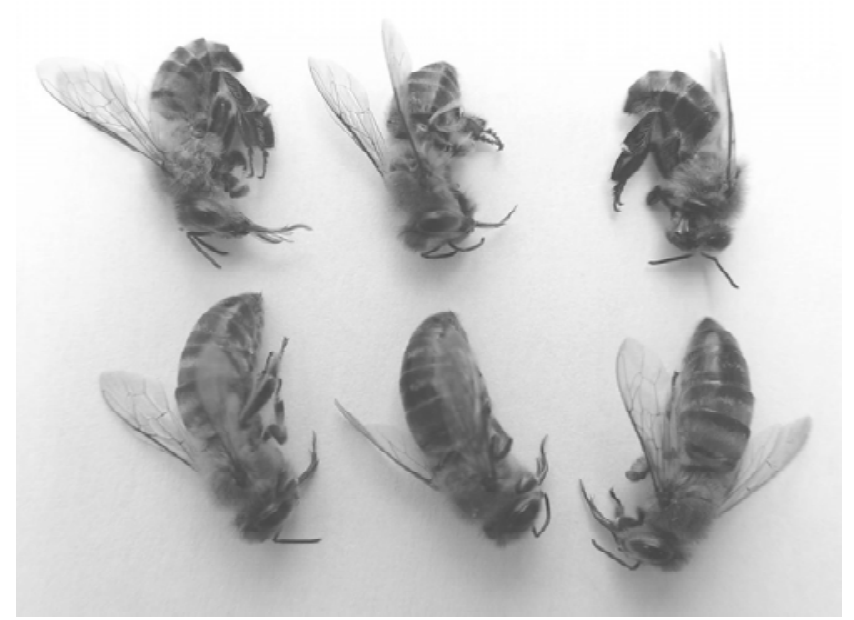

FIGURA 4 - Adultos de Apis mellifera com intumescimento abdominal após o tratamento com Dipel ${ }^{\circledR} 32$ PM (abaixo) e adultos da testemunha (acima). 


\section{CONCLUSÕES}

1. B. thuringiensis var. kurstaki presente no Dipel ${ }^{\circledR}$, é comprovadamente tóxico a adultos de $A$. mellifera.

2. O Dipel ${ }^{\circledR}$ na concentração de $0,25 \mathrm{~g} / 100 \mathrm{~mL}$ adicionado à solução aquosa de mel a $50 \%$ não provocou mortalidade de abelhas.

3. $\mathrm{A} \mathrm{CL}_{50}$ B. thuringiensis var. kurstaki incorporado à pasta Cândi é de 0,325 $\mathrm{g}$ do Dipel ${ }^{\circledR} / 60 \mathrm{~g}$ de pasta Cândi e a $\mathrm{CL}_{90} 2,127 \mathrm{~g}$.

4. $\mathrm{A} \mathrm{CL}_{50}$ do B. thuringiensis var. kurstaki/100 mL de solução aquosa de mel $50 \%$ é de 1,403 e a $\mathrm{CL}_{90}$ é de $7,759 \mathrm{~g}$.

\section{REFERÊNCIAS BIBLIOGRÁFICAS}

ABBOTT, W. S. A method of computing the effectiveness of an insecticide. Journal of Economic Entomology, College Park, v. 18, p. 265-267, 1925.

ANDERSON, D. L. Pest and pathogens of the honeybee (Apis mellifera L.) in Fiji. Journal of Apicultural Research, [S.1.], v. 29, n. 1, p. 53-59, 1990.

ARANTES, O. M. N. Caracterização molecular do gene da delta-endotoxina, sua clonagem e transformação em Bacillus thuringiensis Berliner. 1989. 124 f. Tese (Doutorado em Agronomia) - Escola Superior de Agricultura Luiz de Queiroz, Piracicaba, 1989.

BAILEY, L. Honey bee pathology. New York: Academic, 1981. 124 p.

BOLLHALDER, F. Trichogramma for wax moth control. American Bee Journal, Hamilton, v. 139, n. 9, p. 711-712, 1999.

BRIGHENTI, D. M.; CARVALHO, C. F.; CARVALHO, G. A.; GUIMARÃES, C. R.; CARVALHO, S. M. Longevidade de adultos Apis mellifera Linnaeus, 1758 (Hymenoptera: Apidae) pulverizados com Bacillus thuringiensis var. kurstaki (Berliner, 1915). In: CONGRESSO DE PÓSGRADUAÇÃO, 11., 2002, Lavras. Anais... Lavras: UFLA, 2002. CD-ROM.

BURGES, H. D. Control of wax moths: physical, chemical and biological methods. Bee World, Bucks, v. 59, n. 4, p. 129-138, 1978.

BURGES, H. D.; BAILEY, L. Control of the greater and lesser wax moths (Galleria mellonella and Achroia grisella) with
Bacillus thuringiensis. Journal of Invertebrate Pathology, Riverside, v. 11, n. 2, p. 184-195, 1968.

CARVAlHO, E. M.; CARVALHO, S. M.; CARVALHO, C. F.; CARVALHO, G. A.; SOUZA, B. Impacto de inseticidas fornecidos a adultos de Apis mellifera Linnaeus, 1758 (Hymenoptera: Apidae) por meio de pasta Cândi contaminada. In: CONGRESSO BRASILEIRO DE APICULTURA, 14., 2002, Campo Grande. Anais... Campo Grande: CBA, 2002. p. 114.

CHARRIÈRE, J. D.; IMDORF, A. Protecion of honey combs from wax moth damage. American Bee Journal, [S.1.], v. 139, n. 8, p. 627-630, 1999.

DIAS, L. F. Controle biológico da traça da cera. Informativo Zum Zum, [S.1.], v. 35, n. 301, p. 7, 2001.

FINNEY, D. J. Probit analysis. 3. ed. Cambridge: Cambridge University, 1971. $333 \mathrm{p}$.

GRAMACHO, K. P. Fatores que interferem no comportamento higiênico das abelhas. In: CONGRESSO BRASILEIRO DEAPICULTURA, 14., 2002, Campo Grande. Anais... Campo Grande: CBA, 2002. p. 170.

HEIMPEL, A. M.; ANGUS, T. S. Bacterial insecticides. Bacteriological Reviews, [S.1.], v. 29, n. 3, p. 266-288, 1960.

JYOTI, J. L.; BREWER, G. J. Honey bees (Hymenoptera: Apidae) as vectors of Bacillus thuringiensis for control of banded sunflower moth (Lepidoptera: Tortricidae). Environmental Entomology, College Park, v. 28, n. 6, p. 1172-1176, 1999.

KADO, C. I.; HESKETT, M. G. Selective media for isolation of Agrobacterium, Corynebacterium, Erwinia, Pseudomonas and Xanthomonas. Phytopathology, Saint Paul, v. 60, n. 6, p. 969-976, 1970.

MENDONÇA, P. C. Caracterização e sequenciamento dos plasmídeos pMC1 e pMC2 de Bacillus thuringiensis var. thuringiensis isolado T01 328. 2002. 53 f. Dissertação (Mestrado em Agronomia/Genética Melhoramento de Plantas) - Universidade Estadual Paulista, Jaboticabal, 2002.

NAVON, A. Control of lepidopteran pests with Bacillus thuringiensis. In: ENTWISTLE, P. F.; CORY, J. S.; BAILEY, M. J.; HIGGS, S. Bacillus thuringiensis, an environmental biopesticide: theory and practice. Chichester: Wiley, 1993. 311 p. 
OIRSA, B. Manejo y control de la abeja africanizada Programa Regional para el Manejo y Control de la Abeja Africanizada. El Salvador: [s.n.], 1988. 229 p.

PEREIRA, R. M.; ALVES, S. B.; REIS, P. R. Segurança no emprego de entomopatógenos. In: ALVES, S. B. (Ed.). Controle microbiano de insetos. 2. ed. Piracicaba: FEALQ, 1998. 1163 p.

PREISLER, H. K.; ROBERTSON, J. L. Analysis of timedose-mortality data. Journal of Economic Entomology, College, Park, v. 82, p. 1534-1542, 1989.

SCHENK, E. O apicultor brasileiro: guia completo de apicultura no Brasil. 7. ed. [S.1.: s.n.], 1938. 320 p.

SCOTT, A. J.; KNOTT, M. A. A cluster analysis method for grouping means in the analysis of variance. Biometrics, Washington, v. 30, n. 3, p. 502-512, 1974.

SINGH, S. Beekeeping in India. New Delhi: Indian Council Agricultural Research, 1962. 214 p.

SZABO, T. I.; HEIKEL, D. T. Fumigation with $\mathrm{SO}_{2}$ to control dried fruit moth in honeybee combs. Bee World, Bucks, v. 68, n. 1, p. 37-38, 1987.
VANDENBERG, J. D.; SHIMANUKI, H. Application methods for Bacillus thuringiensis used to control larvae of the greater wax moth (Lepidoptera: Pyralidae) on stored beeswax combs. Journal of Economic Entomology, College Park, v. 83, n. 3, p. 766-771, 1990a.

VANDENBERG, J. D.; SHIMANUKI, H. Viability of Bacillus thuringiensis and its efficacy for larvae of the greater wax moth (Lepidoptera: Pyralidae) following storage of treated combs. Journal of Economic Entomology, College Park, v. 83, n. 3, p. 760-765, 1990 b.

VERMA, S. K. Studies on the control of greater wax moth, Galleria mellonella L. in Apis cerana F. colonies with the biological insecticide, Dipel. Indian Bee Journal, Nainital, v. 57, n. 3, p. 121-123, 1995.

ZANUNCIO, J. C. Efeito do controle químico e microbiológico sobre três pragas de eucalipto e outros insetos. 1976. 76 f. Dissertação (Mestrado em Entomologia) - Universidade Federal de Viçosa, Viçosa, 1976. 